\title{
Tusen: A thousand lakes in the Norwegian landscape
}

\author{
This article belongs to Ambio's 50th Anniversary Collection. Theme: Acidification
}

\author{
David F. Brakke
}

Published online: 8 December 2020

As fall arrived in 1986 and lake water columns were circulating, an incredible team of scientists at the Norwegian Institute for Water Research (NIVA) embarked on a very ambitious project. They surveyed the chemistry of a thousand lakes across Norway, from the north to the south, across a landscape of great distance and with significant topographic relief. It was a major logistical undertaking to sample lake water outlets and have the samples arrive within days for analysis at NIVA.

The Thousand Lake Survey (Tusen) painted a picture of lake water quality in Norway. It also told the story of acidification impacts on water chemistry and fish populations in Norway. A picture painted by many colored points and a story, while amazing and impressive, were all built on a history of concerted effort and research on lake water acidification conducted by NIVA over many years, including previous regional surveys in 1974-1975.

The team of scientists conducting the survey were led and directed by Dr. Arne Henriksen, a pioneer in research on the impacts of acid rain on aquatic ecosystems. They managed to sample the thousand lakes and process all of the water samples with extreme care and with the highest quality control. The Thousand Lake Survey was one of the crowning achievements of NIVA, along with many others, to underscore the impacts of transboundary air pollution impacts on dilute and sensitive lake systems in Norway. Many of the readers of Ambio will know the numerous accomplishments documented in the many reports and publications emanating from NIVA by Arne Henriksen, Dick Wright, Bjørn Olav Rosseland, and others.

Back to the Thousand Lake Survey and its meaning. At the time, other surveys of lakes were being conducted, including the Eastern and Western Lake Surveys in the United States, in which I was also involved, and a notable survey of lakes in Finland. The surveys in the U.S. were designed to answer a simple question from the Administrator of the U.S. Environmental Protection Agency at the time, Bill Ruckeleshaus, on "how many acidic lakes are there in the Adirondacks?" No one could give him an answer. The surveys in the U.S. were based on a statistical design to be representative of the lake water chemistry of areas determined to be sensitive to acidification in the US. The surveys were conducted in consecutive years and produced many important results.

After the two U.S. surveys were done by the U.S. Environmental Protection Agency and the reports were completed, I had a sabbatical leave opportunity from my university. With a fellowship from the Royal Norwegian Academy of Sciences I was able to spend a very special year at NIVA. I had been in Norway for a sampling of humic lakes in two different areas of Norway in September and returned in December as the results from the Thousand Lake Survey were coming in. A fellow traveler for the year was Steve Norton, a geochemist from the University of Maine. Coffee conversations led to many publications and other analyses, including an experimental demonstration of the sea-salt effect in a small catchment located $1000 \mathrm{~m}$ above the Sognefjord led by Dick Wright. Those results were published in Nature (Wright et al. 1988a). I should note that not all of the discussions were serious. One of the acknowledgements in one of the published papers was to Glen F. Iddich.

The initial report on the Thousand Lake Survey was published in Norwegian. I had the task and pleasure of translating it into English. That report in English was published as "The Thousand Lake Survey 1986, Norway, by the Norwegian State Pollution Control Authority. The results of the Norwegian lake survey in 1986 were plotted in colored point maps. Given the tall and thin shape of the country, projection of the results was difficult. We greatly 
appreciated how Ambio formatted the report we published such that the results could be viewed across the entire country (Henriksen et al. 1988). The colored dots painted the picture better than our written words. The color blue was chosen to represent the best environmental conditions, while green to orange to red indicated increasing impacts of acidic deposition.

Acid neutralizing capacity (ANC) in lakes is derived from weathering and ion exchange in a watershed. Bedrock and soil are the main sources of base cations, principally calcium and magnesium, with soil thickness and hydrologic flow path both being important factors in determining the concentrations of base cations. $\mathrm{Ca}$ and $\mathrm{Mg}$ were quite low in many of the lakes sampled. More than $45 \%$ of the area in Norway is underlain by bedrock that produces runoff water with low bicarbonate buffering. Some of the lakes at higher elevations had extremely low concentrations and are among the most dilute lakes in the world. With low base cation concentrations, many of the lakes were sensitive to acidification resulting from high sulfate concentrations related to acidic deposition. The highest concentrations of sulfate in lakes were observed in southernmost Norway and in southeastern Norway with concentrations declining to the north. The pattern corresponded with the $\mathrm{pH}$ of precipitation. Lakes with $\mathrm{pH}$ values less than 5.0 were found when annual precipitation is $\mathrm{pH} 4.7$ or less, which occurred in large portions of southernmost and southeastern Norway. Those acidic lakes usually had high concentrations of aluminum, sulfate, and nitrate and had lost fish populations.

The linkage between acidic deposition and lake acidification leading to the loss of fish populations was being demonstrated by surveys and experiments. The reversibility of acidification was being shown by liming experiments, including Gårdsjön in Sweden, and the wholecatchment experiments being done by Dick Wright at NIVA (The RAIN Project) in Norway. However, there were critics of the conclusion that anthropogenic air pollution was the cause of lake acidification.

In an earlier "controversy" over eutrophication, where some proposed $\mathrm{C}$ as a major limiting nutrient, a series of whole-lake fertilization experiments done by David Schindler and colleagues at the Experimental Lakes Area in northwestern Ontario demonstrated that phosphorus was the most important element limiting algal growth and that increasing phosphorus concentrations produces blooms of Cyanobacteria. Some skeptics argued that natural sources of acidity were contributing and important factors in lake and stream acidification. The arguments were so many that we published a paper titled 'Red herring' lakes and streams in the acid rain literature (Norton et al. 1989).

Especially in boggy terrains, humic compounds stain water with a yellowish-brown color. Humic waters contain humic acids. The Thousand Lake Survey used total organic carbon (TOC) concentrations as an estimate of the potential contribution of humic acids to acidity. In the survey, $60 \%$ of the lakes had low concentrations of TOC. Lakes with higher TOC concentrations were only in southern and eastern Norway where the soils are generally thicker. TOC decreased with elevation and was at very low concentrations above timberline. Additional sampling of humic lakes in different parts of Norway showed the relative contributions of humic acids to acidity. The overall contribution of humic acids to acidity in the Thousand Lake Survey was quite low. Humic acids contributed little to no acidity across the population of lakes sampled.

Almost a third of the lakes in the 1986 survey had been sampled in the fall of 1974 or 1975 . For those lakes a direct comparison was made. There was a slight tendency for higher lake water $\mathrm{pH}$ in 1986. Lakes that had the highest sulfate concentrations showed a tendency to lower levels, however, nitrate concentrations were higher, adding to the contribution of sulfate to acidity. Also increasing were aluminum concentrations.

Reductions in acidic deposition had been proposed as part of international agreements (see Grennfelt et al. 2020 for an excellent summary of acid rain science and policy over a 50-year period, both terrestrial and aquatic impacts). With reductions in emissions of acidic precursors, lake water acidity was expected to decrease. Our Ambio article described a modeling effort to estimate the impact of lakes to varying reductions in the emission of sulfur dioxide. At the time a common expectation was for a $30 \%$ reduction in emissions within 10 years. For the 786 lakes sampled in southern Norway, we modeled reductions of 30, 50, 70, and $100 \%$ in sulfur deposition. In 1986, roughly $70 \%$ of the lakes had no bicarbonate buffering, or positive strong acids. With a $30 \%$ reduction in emissions, we predicted the percentage of acidic lakes would decline to $55 \%$. Even with a $50 \%$ reduction in emissions $45 \%$ of the lakes were expected to still be acidic.

Figure 7 in our original article (reproduced here as Fig. 1) illustrates the changes in present levels of strong acid concentrations and what was anticipated by a $50 \%$ reduction in acid deposition. That striking figure was a very colorful representation of what recovery of lakes might look like across southern and eastern Norway. In many ways, the data and the modeling demonstrated how very sensitive the lakes are. Even with $100 \%$ reduction in acidic deposition, we predicted some lakes would still have no or very low buffering but none of them would have a $\mathrm{pH}$ below 5.0.

One of the considerations that emerged from the evidence of impaired aquatic ecosystems was to look at critical loads of deposition, that is, the loads beyond which we would expect acidification to occur, and levels to which 
Figure 7. Strong acid concentrations in 786 lakes in southern Norway in

1986 and calculated for $50 \%$ reduc-

tions in sulfur deposition.

- Less than -10

- From -10 to +10

- From +10 to +25

- Greater than +25

\section{Present levels}

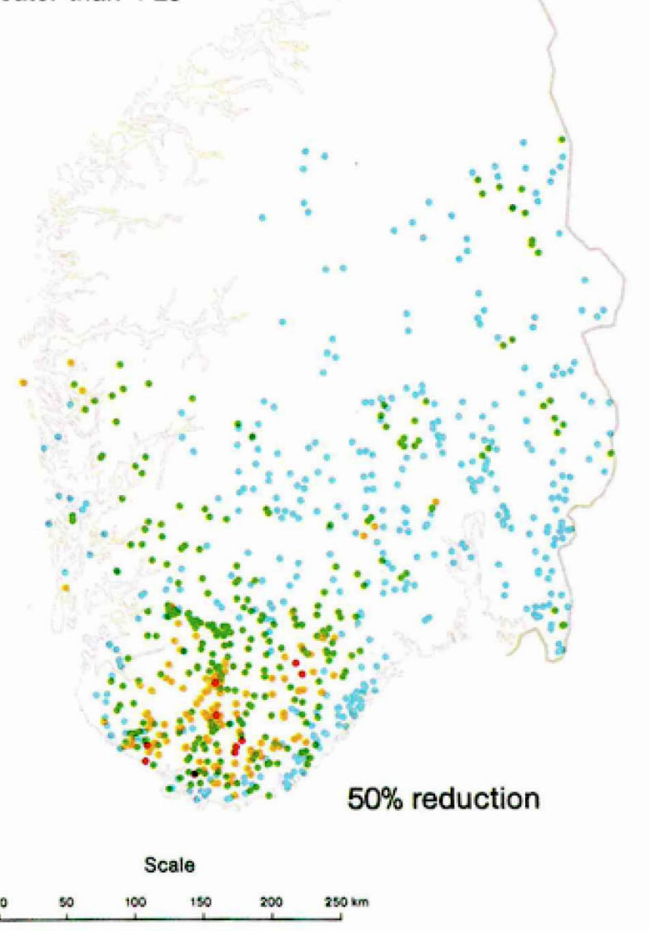

Fig. 1 Reprint of Fig. 7 from the original article (Henriksen et al. 1988) 
emissions must be reduced in order to achieve recovery. The Thousand Lake Survey and other survey results were very important in making estimates of what critical levels were necessary to achieve.

The acidic lakes in all areas typically had high concentrations of aluminum, sulfate, and nitrate and had lost fish populations. With decreased deposition, higher $\mathrm{pH}$ and lower concentrations of aluminum and sulfate, fish populations could be restored (see Henriksen et al. 1989). Reversibility of acidification was a question and it was demonstrated experimentally by Wright et al. (1988b), which was followed by a more comprehensive analysis of the recovery of acidified waters in Europe by Wright et al. (2005).

It was the loss of fish populations that signaled something was happening to the lakes in Norway and triggered a long series of very high quality surveys and experiments by an amazing group of scientists at the Norwegian Institute for Water Research. The empirical observations helped stimulate other research in many countries to understand the acidification impacts of air pollution on aquatic ecosystems. The lake surveys conducted in 1974-1975 set the stage. The Norwegian lake survey in 1986 made the linkage between acid deposition and lake acidification clear. Henriksen et al. (1989) reported on the status of fish populations at the time and predicted how they may improve with reductions in deposition.

\section{REFERENCES}

Grennfelt, P., A. Engleryd, M. Forsius, O. Hov, H. Rodhe, and E. Cowling. 2020. Acid rain and air pollution: 50 years of progress in environmental science and policy. Ambio 49: 849-864. https:// doi.org/10.1007/s13280-019-01244-4.

Henriksen, A., L. Lien, T.S. Traaen, I.S. Sevaldrud, and D.F. Brakke. 1988. Lake acidification in Norway-present and predicted chemical status. Ambio 17: 259-266.

Henriksen, A., L. Lien, B.O. Rosseland, T.S. Traaen, I.S. Sevaldrud, and D.F. Brakke. 1989. Lake acidification in Norway-Present and predicted fish status. Ambio 18: 314-321.

Norton, S.A., D.F. Brakke, and A. Henriksen. 1989. 'Red herring' lakes and streams in the acid rain literature. Science of the Total Environment 83: 113-125.

Wright, R.F., L. Camerero, B.J. Cosby, R.C. Ferrier, M. Forsius, R. Helliwell, A. Jenkins, J. Kopacek, et al. 2005. Recovery of acidified European surface waters. Environmental Science and Technology 39: 64A-72A.

Wright, R.F., E. Lotse, and A. Semb. 1988b. Reversibility of acidification shown by whole-catchment experiments. Nature 334: 670-675.

Wright, R.F., S.A. Norton, D.F. Brakke, and T. Frogner. 1988a. Experimental verification of episodic acidification of freshwaters by sea salts. Nature 334: 422-424.

Publisher's Note Springer Nature remains neutral with regard to jurisdictional claims in published maps and institutional affiliations.

David F. Brakke ( $\square)$

Address: 149 Marshall Point Road, P.O. Box 113, Pt. Clyde, ME 04855, USA.

e-mail: brakkedf@jmu.edu 